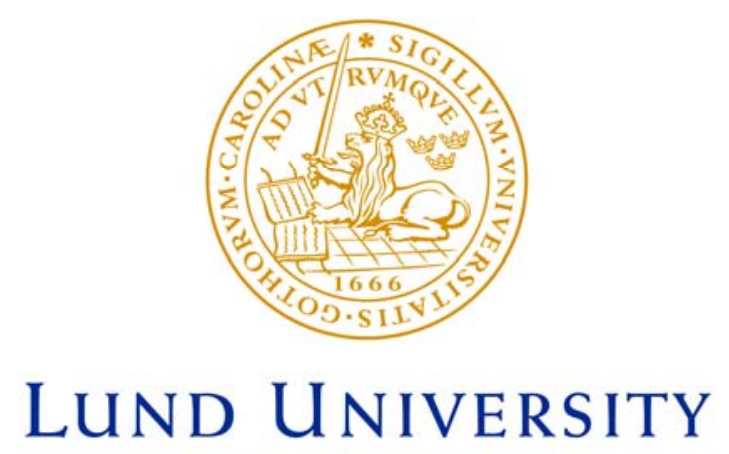

Faculty of Medicine

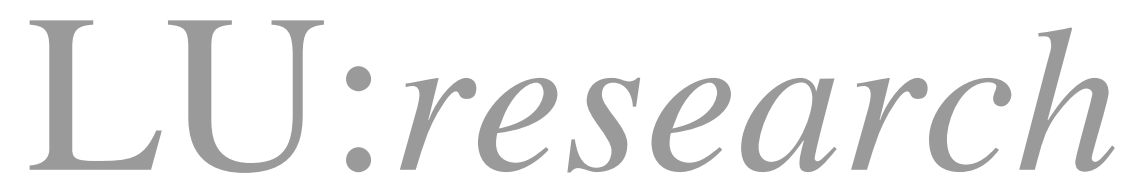

Institutional Repository of Lund University

This is an author produced version of a paper published in International journal of geriatric psychiatry. This paper has been peer-reviewed but does not include the final publisher proof-corrections or journal pagination.

Citation for the published paper:

Andersson, $\mathrm{M}$ and Hansson, $\mathrm{O}$ and Minthon, $\mathrm{L}$ and Ballard, C G and Londos, E.

"The period of hypotension following orthostatic challenge is prolonged in dementia with Lewy bodies." Int J Geriatr Psychiatry, 2007, Jul 10; [Epub ahead of print]

http://dx.doi.org/10.1002/gps. 1861

Access to the published version may

require journal subscription.

Published with permission from: Wiley 


\section{The period of hypotension following orthostatic challenge is prolonged in dementia with Lewy bodies}

Running head: Orthostatic hypotension in DLB

M. Andersson, O. Hansson, MD, PhD, L. Minthon, MD, PhD, C.G. Ballard, MD, E. Londos, $\mathrm{MD}, \mathrm{PhD}$

From the Neuropsychiatric clinic, Malmö University Hospital, Malmö, Sweden (M.

Andersson, O. Hansson, L. Minthon, E. Londos), Clinical Memory Research Unit, Department of Clinical Sciences, Malmö, Lund University, Sweden (M. Andersson, O.

Hansson, L. Minthon, E. Londos), Wolfson Centre for Age-Related Diseases, King's College, London, UK (C.G. Ballard).

Corresponding author:

Maria Andersson, Neuropsychiatric clinic, Malmö University Hospital, 20502 Malmö, Sweden

Phone: +46-40-335036, Fax: +46-40-335654, E-mail: Maria_A.Andersson@med.lu.se

Keywords: dementia, Lewy body disease, blood pressure, orthostatic hypotension.

Word count: 2113 words, abstract 238 words

The authors declare no conflicts of interests. 


\section{SUMMARY}

Objectives: To determine whether orthostatic hypotension $(\mathrm{OH})$ is more common in patients with dementia than in older people without cognitive impairment and to identify key differences in the profile of the orthostatic response and the pulse drive during orthostatic challenge between Alzheimer's disease (AD) and dementia with Lewy bodies (DLB).

Methods: The orthostatic response was evaluated in 235 patients with AD, 52 patients with DLB and 62 elderly controls. The blood pressure and pulse rate were measured in supine position, immediately after standing up and after one, three, five and ten minutes of standing. $\mathrm{OH}$ was defined as a reduction of systolic blood pressure (SBP) of at least $20 \mathrm{~mm} \mathrm{Hg}$ or a reduction of diastolic blood pressure (DBP) of at least $10 \mathrm{~mm} \mathrm{Hg}$.

Results: $\mathrm{OH}$ occurred in $69 \%$ of the DLB patients and in $42 \%$ of the AD patients, but only in $13 \%$ of the controls. $(p<0.001$ controls vs $A D$ and controls vs $\mathrm{DLB}, \mathrm{p}=0.001$ AD vs DLB) The DLB patients had a greater drop in SBP than the other study groups during orthostatic challenge and had a more prolonged period of orthostasis. The pulse drive on orthostatic challenge was similar in between groups. However, in the DLB group it was not adequate to restore the blood pressure to supine values.

Conclusions: Patients with DLB react different to orthostatic challenge than patients with AD or controls, with important clinical implications for key disease symptoms and treatment. 


\section{INTRODUCTION}

Worldwide, 25 million people suffer from dementia, the majority of whom have Alzheimer's disease (AD). It is a devastating illness, which results in a progressive decline in cognitive ability and functional capacity, causes immense distress to patients, their carers and families and has an enormous societal impact. Dementia with Lewy bodies (DLB) is often claimed to be the second most common cause of neurodegenerative dementia in older people after AD. A systematic review of six studies has found prevalence estimates for clinical DLB of up to $30.5 \%$ of all dementia cases.(Zaccai et al., 2005) The central feature of DLB is progressive cognitive decline accompanied by fluctuating cognition, visual hallucinations and parkinsonism. Suggestive features are REM sleep behaviour disorder, severe neuroleptic sensitivity and low dopamine transporter uptake in basal ganglia. Some of the supportive features are falls, syncope, loss of consciousness, systematised delusions, hallucinations of other modalities, depression, autonomic failure and abnormal metaiodobenzyl guanidine (MIBG) myocardial scintigraphy.(McKeith et al., 1996; McKeith et al., 1999; McKeith et al., 2005)

Orthostatic hypotension $(\mathrm{OH})$ is a common problem amongst older people living in the community, with prevalence between $4 \%$ and $33 \%$ depending on the methodology used and differences in population characteristics. The frequency increases with age.(Mathias et al., 1999b; Kenny et al., 2002) A review published in 2005 focussing on the diagnosis of DLB, concluded that autonomic function, such as $\mathrm{OH}$ has not been adequately studied, although preliminary reports indicate that it is a major problem in these patients.(Geser et al., 2005)

The effect of standing up on blood pressure and pulse reaction is important to clarify for several reasons. First, it might be used as an instrument to differentiate different types of 
dementia from each other. This will have clinical implications as DLB patients show good responsiveness to cholinesterase inhibitors but extreme sensitivity to the side effects of neuroleptic drugs. It is also important since the course and prognosis may differ from other dementias.(Geser et al., 2005) Second, it is important to recognise a low blood pressure in patients with dementia as many of the drugs used to treat dementia have blood pressure lowering properties and specific interventions may be necessary to improve related symptoms and reduce the risk of falls.

The current study aimed to determine whether $1: \mathrm{OH}$ is more common in patients suffering from dementia than in older people without cognitive impairment, 2: the profile of the orthostatic response is different in DLB and AD, 3: the pulse drive during orthostatic measurement differs between DLB, AD and elderly controls.

\section{METHODS}

\section{Study population}

Two hundred and eighty seven patients (235 AD, 52 DLB) from the Malmö Alzheimer's study and 62 controls were assessed. All the patients attended the Neuropsychiatric Clinic, Malmö University Hospital, Malmö, Sweden and were evaluated with a detailed clinical investigation of cognitive function during 1999-2003. The complete investigation included anamnestic data, physical and neuropsychiatric examination, tests of cognitive function (Mini Mental State Examination (MMSE) (Folstein et al., 1975) and Alzheimer's Disease Assessment Scale (ADAS) (Mohs et al., 1983)), blood and cerebrospinal fluid (CSF) sampling, brain $\mathrm{CT}$, regional cerebral blood flow (rCBF), EKG and blood pressure measurements. Only AD patients showing mild or moderate disease and with a complete 
investigation were selected to participate in the study. All patients diagnosed with DLB during the study interval were included. More than $90 \%$ of the patients were living in the community, 7 of the AD patients and 3 of the DLB patients were living in nursing homes. The diagnosis was given prospectively using operationalized diagnostic criteria (NINCDSADRDA (McKhann et al., 1984) for probable AD and DLB consensus criteria for probable DLB (McKeith et al., 1996)).

The controls $(\mathrm{n}=62)$ were recruited through advertisements. Volunteers went through physical examination and cognitive testing. Inclusion criteria were absence of memory complaints or any other cognitive symptoms, preservation of general cognitive functioning and no active neurological or psychiatric disease. Individuals with other medical conditions that did not affect cognition where not excluded.

\section{Blood pressure measurements}

Orthostatic blood pressure was measured at the patient's first visit at the clinic. The measurement was performed in accordance to a standardised scheme using a validated digital sphygmomanometer (OMRON M5-1) over the brachial artery.(El Assaad et al., 2003) The blood pressure and pulse rate were recorded after at least ten minutes rest in a supine position, immediately after standing up, and after one, three, five and ten minutes of standing. All subjects stood up by themselves without assistance. OH was defined as a reduction of SBP of at least $20 \mathrm{~mm} \mathrm{Hg}$ or a reduction of DBP of at least $10 \mathrm{~mm} \mathrm{Hg}$. (The Consensus Committee of the American Autonomic Society and the American Academy of Neurology) Some of the orthostatic measurements were incomplete (3\% of the controls, $15 \%$ of the AD patients and $20 \%$ of the DLB patients). The most frequent reasons for not completing the measurement were apparatus failure, orthostatic symptoms, patients being unable to stand for ten minutes 
and patients unwilling to participate. In the evaluation of $\mathrm{OH}$ both patients with complete and incomplete orthostatic measurements were included.

The study was approved by the ethics committee of Lund University.

\section{Statistical analysis}

Statistical analysis was performed with use of The Statistical Package for Social Sciences (SPSS) software version 12.0.1. To avoid bias with non-normally distributed variables nonparametric statistics (Kruskal-Wallis and Mann-Whitney U test) were used to detect significant group differences. Binary variables were compared using Chi-Square Tests.

\section{RESULTS}

In this study on the reaction to orthostatic challenge we included 62 controls, $235 \mathrm{AD}$ patients and 52 DLB patients. There was no significant difference in age or mean MMSE score between the $\mathrm{AD}$ and the DLB patients (table 1). [Insert table 1 about here] The use of medications known to influence the blood pressure was compared between the groups (table 2). The drugs were classified by the Anatomical Therapeutic Chemical classification system (ATC) recommended by the World Health Organization (WHO). (Guidelines for ATC classification and DDD assignment. Oslo: WHO Collaboration Centre for Drug Statistics Methodology; 2001. http://www.whocc.no) The use of antidepressants was more prevalent among $\mathrm{AD}$ and DLB patients compared to the controls. The use of medication in the group "antipsychotics, anxiolytics and sedatives" also differed in between all three groups (table 2). [Insert table 2 about here] The blood pressure (BP) and pulse rate were analysed for all included patients as well as for the orthostatic patients only. To compare the different profiles of the orthostatic response, the mean drop in BP from supine rest at each measurement point (standing, $1 \mathrm{~min}, 3 \mathrm{~min}, 5 \mathrm{~min}$ and $10 \mathrm{~min}$ ) was calculated. As shown in figure 1 the DLB 
patients had a greater drop in SBP than the other study groups during orthostatic challenge. Moreover, they had a more prolonged period of orthostasis (figure 1). [Insert figure 1 about here] We found that $\mathrm{OH}$ occurred in $36(69 \%)$ of the DLB patients, in $99(42 \%)$ of the AD patients and in $8(13 \%)$ of the controls. The differences were significant ( $p<0.001$ AD vs. controls and DLB vs controls, $\mathrm{p}=0.001 \mathrm{AD}$ vs DLB).

The profiles of the orthostatic patients $(n=143)$ are illustrated in figure 2 A and show that the DLB patients with $\mathrm{OH}$ have a larger and more prolonged drop of SBP, when compared to AD or controls with $\mathrm{OH}$. The pulse drive on orthostatic challenge was similar in all groups (figure 2B). [Insert figure 2 about here]

To illustrate the duration of orthostasis in the different diagnostic groups, each patient's systolic blood pressure curve was analysed individually. Each measurement point (standing, 1 min, $3 \mathrm{~min}, 5 \mathrm{~min}, 10 \mathrm{~min}$ ) was dichotomised as orthostatic or not orthostatic. The sum of all orthostatic values (0-5) in each individual was calculated. The minimum value zero is possible because $\mathrm{OH}$ was defined by both systolic and diastolic drop. The number of orthostatic measurement points was increased in the DLB group compared to both the control group and the AD group. (table 3) [Insert table 3 about here]

The use of antipsychotics, anxiolytics and sedatives differed between the two dementia groups. (table 2) To investigate the effect of these drugs on the orthostatic response the DLB and $\mathrm{AD}$ groups were divided in two groups respectively, one with the above mentioned medication and one without, and the profiles of the orthostatic responses were compared. (figure 3) There were no significant differences between the DLB patients taking the medication and the ones not taking the medication. The AD and DLB subjects taking the 
medication differed significantly on all measurement points $(\mathrm{p}<0.001)$. The AD and DLB patients not taking the medication differed significantly on standing $(\mathrm{p}=0.017)$, after $1 \mathrm{~min}$ $(\mathrm{p}=0.004)$, after $3 \mathrm{~min}(\mathrm{p}=0.014)$ and after $10 \mathrm{~min}(\mathrm{p}=0.009)$ of standing. [Insert figure 3 about here]

\section{DISCUSSION}

In the largest study of $\mathrm{OH}$ in patients with DLB, we determined that DLB patients had a greater drop in blood pressure during orthostatic challenge over 10 minutes, than patients with $\mathrm{AD}$ or elderly controls. Furthermore we report an important new finding, demonstrating that DLB patients had a significantly more protracted period of orthostasis than AD patients. The pulse drive was similar in $\mathrm{DLB}$ and $\mathrm{AD}$, but the rise in pulse rate was not adequate to restore the blood pressure to supine values in DLB patients. The study also confirmed a significantly higher prevalence of $\mathrm{OH}$ in patients suffering from dementia compared to older people without dementia.

The blood pressure measurements were standardised and detailed. It is important to test for $\mathrm{OH}$ during 10 minutes of standing since patients, and dementia patients in particular, may not manifest significant falls in blood pressure until after five minutes of standing or more.(Passant et al., 1996) The measurements were carried out from approximately 8 am to 5 pm. There seem to be only minor natural blood pressure alterations during this time in healthy elderly men.(Bjorklund et al., 2000) In patients suffering from $\mathrm{OH}$ the orthostatic reaction and its symptoms may be worse in the morning.(Mathias et al., 1999a; Mathias et al., 1999b) In this study $82 \%$ of the controls, $51 \%$ of the AD patients and $61 \%$ of the DLB patients had their orthostatic measurements carried out before noon. There were no significant differences in the 
frequency of orthostatic reactions between the individuals in the same group regarding whether they had had their measurement carried out before or after noon (data not shown).

The control group was healthier than the dementia groups regarding cardiac disease and the use of antidepressants and other psychoactive drugs. Importantly, the only significant difference between the AD and the DLB group concerned the use of antipsychotics, anxiolytics and sedatives. The difference in medication between the dementia groups is not likely to alone explain the differences in blood pressure reaction to orthostatic challenge, since the difference in systolic drop between the AD and the DLB patients taking the medication was highly significant as well as the difference in systolic drop between the AD and DLB patients not taking the medication. There was no significant difference in systolic drop between the DLB patients with and without the medication, although the medication seemed to aggravate the $\mathrm{OH}$ in DLB. This is important to be aware of in the clinic, in order to avoid worsening of $\mathrm{OH}$ in these patients. The diagnosis of probable DLB was given using the 1996 DLB consensus criteria which do not include autonomic dysfunction as a supportive feature.(McKeith et al., 1996)

It has been shown that $\mathrm{AD}$, fronto-temporal dementia and vascular dementia patients have normal pulse reactions during orthostatic testing.(Passant et al., 1997) Our results show that this is also true for DLB. This indicates that the heart is normally activated but not enough, since the DLB patients stay orthostatic, and the failure might also be in the sympathetic activation of the vasculature. In a neuropathological study from 2005 Benarroch et al suggests that $\mathrm{OH}$ in DLB and Parkinson's disease may be due to degeneration of sympathetic ganglion neurones.(Benarroch et al., 2005) A new method to distinguish DLB from AD is $\left[{ }^{123} \mathrm{I}\right] \mathrm{MIBG}$ myocardial scintigraphy, which has shown reduced uptake of norepinephrine precursors in 
cardiac sympathetic terminals in DLB compared to AD.(Watanabe et al., 2001; Yoshita et al., 2001) The results further underscore the postganglionic pattern of involvement of the autonomic nervous system in DLB.

Dysautonomia, including $\mathrm{OH}$, has been highlighted as a supportive feature for the diagnosis of DLB in the new consensus criteria, but was not given a more prominent place in diagnosis because of the paucity of empirical data.(McKeith et al., 2005) This study shows that the profile of the orthostatic reaction is different between dementia groups. DLB has the greatest

drop in blood pressure and most longstanding reaction to orthostatic challenge. This may have clinical implications for treatment as well as for understanding the neurophysiological properties of the disease. Further studies are needed to determine if $\mathrm{OH}$ can play a more important role in the diagnosis of DLB.

\section{ACKNOWLEDGEMENTS}

Carina Wattmo for statistical advice. AnnaCarin Björkman and Cecilia Dahl for administration of patient material. Sassa Persson for technical information on blood pressure measurement instruments.

\section{FUNDING}

The study was supported by the Alzheimer Foundation, Sweden.

\section{REFERENCES}

Benarroch EE, Schmeichel AM, Low PA, et al. 2005. Involvement of medullary regions controlling sympathetic output in Lewy body disease. Brain 128: 338-344. 
Bjorklund K, Lind L and Lithell H. 2000. Twenty-four hour ambulatory blood pressure in a population of elderly men. J Intern Med 248: 501-510.

El Assaad MA, Topouchian JA and Asmar RG. 2003. Evaluation of two devices for selfmeasurement of blood pressure according to the international protocol: the Omron M5-I and the Omron 705IT. Blood Press Monit 8: 128-133.

Folstein MF, Folstein SE and McHugh PR. 1975. "Mini-mental state". A practical method for grading the cognitive state of patients for the clinician. J Psychiatr Res 12: 189-198.

Geser F, Wenning GK, Poewe W, et al. 2005. How to diagnose dementia with Lewy bodies: State of the art. Mov Disord 20: S11-S20.

Kenny RA, Kalaria R and Ballard C. 2002. Neurocardiovascular instability in cognitive impairment and dementia. Ann N Y Acad Sci 977: 183-195.

Mathias CJ and Bannister R. 1999a. Investigation of autonomic disorders. In Autonomic Failure. A Textbook of Clinical Disorders of the Autonomic Nervous System. $4^{\text {th }}$ ed , C. J. Mathias and R. Bannister (eds). Oxford University Press; 169-193.

Mathias CJ and Kimber JR. 1999b. Postural hypotension: Causes, Clinical Features, Investigation, and Management. Annu Rev Med 50: 317-336.

McKeith IG, Dickson DW, Lowe J, et al. 2005. Diagnosis and management of dementia with Lewy bodies. Third report of the DLB consortium. Neurology 65: 1863-1872.

McKeith IG, Galasko D, Kosaka K, et al. 1996. Consensus guidelines for the clinical and pathologic diagnosis of dementia with Lewy bodies (DLB): report of the consortium on DLB international workshop. Neurology 47: 1113-1124.

McKeith IG, Perry EK and Perry RH. 1999. Report of the second dementia with Lewy body international workshop: diagnosis and treatment. Consortium on Dementia with Lewy Bodies. Neurology 53: 902-905. 
McKhann G, Drachman D, Folstein M, et al. 1984. Clinical diagnosis of Alzheimer's disease: report of the NINCDS-ADRDA Work Group under the auspices of Department of Health and Human Services Task Force on Alzheimer's Disease. Neurology 34: 939944.

Mohs RC, Rosen WG and Davis KL. 1983. The Alzheimer's disease assessment scale: an instrument for assessing treatment efficacy. Psychopharmacol Bull 19: 448-450.

Passant U, Warkentin S and Gustafson L. 1997. Orthostatic hypotension and low blood pressure in organic dementia: a study of prevalence and related clinical characteristics. Intl J Geriatr Psychiatry 12: 395-403.

Passant U, Warkentin S, Karlson S, et al. 1996. Orthostatic hypotension in organic dementia: relationship between blood pressure, cortical blood flow and symptoms. Clin Auton Res 6: 29-36.

The Consensus Committee of the American Autonomic Society and the American Academy of Neurology. 1996. Consensus Statement on the definition of orthostatic hypotension, pure autonomic failure, and multipel system atrophy. Neurology 46: 1470.

Watanabe H, Ieda T, Katayama T, et al. 2001. Cardiac 123I-meta-iodobenzylguanidine (MIBG) uptake in dementia with Lewy bodies: comparison with Alzheimer's disease. J Neurol Neurosurg Psychiatry 70: 781-783.

Yoshita M, Taki J and Yamada M. 2001. A clinical role for [123I]MIBG myocardial scintigraphy in the distinction between dementia of the Alzheimer's-type and dementia with Lewy bodies. J Neurol Neurosurg Psychiatry 71: 583-588.

Zaccai J, McCracken C and Brayne C. 2005. A systematic review of prevalence and incidence studies of dementia with Lewy bodies. Age ageing 34: 561-566. 


\section{TABLES}

Table 1, demographic data

\begin{tabular}{llll}
\hline & Controls $(\mathrm{n}=62)$ & $\mathrm{AD}(\mathrm{n}=235)$ & DLB $(\mathrm{n}=52)$ \\
\hline Median age (years) & 73 & $76^{*}$ & $77^{\dagger}$ \\
Age range & $60-94$ & $52-87$ & $54-89$ \\
Women, n & $41(66 \%)$ & $161(69 \%)^{\ddagger}$ & $23(44 \%)^{\S}$ \\
Mean MMSE & $29 \pm 1$ & $21 \pm 5^{\|}$ & $22 \pm 5^{\natural}$ \\
score \pm SD & & &
\end{tabular}

${ }^{*} \mathrm{p}=0.017$ AD vs controls, ${ }^{\dagger} \mathrm{p}=0.009$ DLB vs controls, ${ }^{\dagger} \mathrm{p}=0.002$ AD vs DLB, ${ }^{\S} \mathrm{p}=0.031$ DLB vs controls, ${ }^{\mathrm{p}}<0.001 \mathrm{AD}$ vs controls, ${ }^{\natural} \mathrm{p}<0.001$ DLB vs controls. 
Table 2, medication and medical history

\begin{tabular}{llll}
\hline & $\begin{array}{l}\text { Controls } \\
(\mathrm{n}=62)\end{array}$ & $\begin{array}{l}\text { AD } \\
(\mathrm{n}=235)\end{array}$ & $\begin{array}{l}\text { DLB } \\
(\mathrm{n}=52)\end{array}$ \\
\hline Antidepressants, $\mathrm{n}$ & $3(5 \%)$ & $98(42 \%)^{*}$ & $26(51 \%)^{\dagger}$ \\
Antipsych/Anx/Sed, $\mathrm{n}$ & $1(2 \%)$ & $74(32 \%)^{\S} \|$ & $28(55 \%)^{\natural}$ \\
Antihypertensives/cardiac & $23(37 \%)$ & $79(34 \%)$ & $19(37 \%)$ \\
therapy, $\mathrm{n}$ & & & \\
Cardiac disease**, n & $8(13 \%)$ & $64(27 \%)^{\dagger \dagger}$ & $18(35 \%)^{*}$ \\
Hypertension, $\mathrm{n}$ & $12(21 \%)$ & $56(24 \%)$ & $18(35 \%)$ \\
Arteriosclerosis $^{\S \S}, \mathrm{n}$ & $10(17 \%)$ & $53(23 \%)$ & $14(27 \%)$
\end{tabular}

${ }^{*} \mathrm{p}<0.001 \mathrm{AD}$ vs controls, ${ }^{\dagger} \mathrm{p}<0.001$ DLB vs controls, ${ }^{\star}$ Antipsychotics, Anxiolytics,

Sedatives/Hypnotics, ${ }^{\S} \mathrm{p}<0.001$ AD vs controls, ${ }_{p}=0.003$ AD vs DLB, ${ }^{\uparrow} p<0.001$ DLB vs controls, **Atrial fibrillation, AV-block I, Congestive heart failure, ${ }^{\dagger \dagger} p=0.03$ AD vs controls, ${ }_{\mathrm{H}}^{\mathrm{f}}=0.011$ DLB vs controls, ${ }^{\S}$ Myocardial infarction, Coronary artery disease, Peripheral artery disease. 
Table 3. Sum of orthostatic measurement points. Systolic values.

\begin{tabular}{|c|c|c|c|c|c|c|}
\hline & $\begin{array}{l}\text { Controls } \\
(n=62)\end{array}$ & $\mathrm{AD}(\mathrm{n}=235)$ & $\operatorname{DLB}(\mathrm{n}=52)$ & $\begin{array}{l}\text { Controls with } \\
\mathrm{OH}(\mathrm{n}=8)\end{array}$ & $\begin{array}{l}\text { AD with } \\
\mathrm{OH}(\mathrm{n}=99)\end{array}$ & $\begin{array}{l}\text { DLB with } \\
\mathrm{OH}(n=36)\end{array}$ \\
\hline Median & 0 & $0 * \dagger$ & $2^{t}$ & 1.5 & $2.0^{\S}$ & $4.0^{\| \prime}$ \\
\hline Range & $0-4$ & $0-5$ & $0-5$ & $1-4$ & $0-5$ & $0-5$ \\
\hline
\end{tabular}




\section{FIGURES}

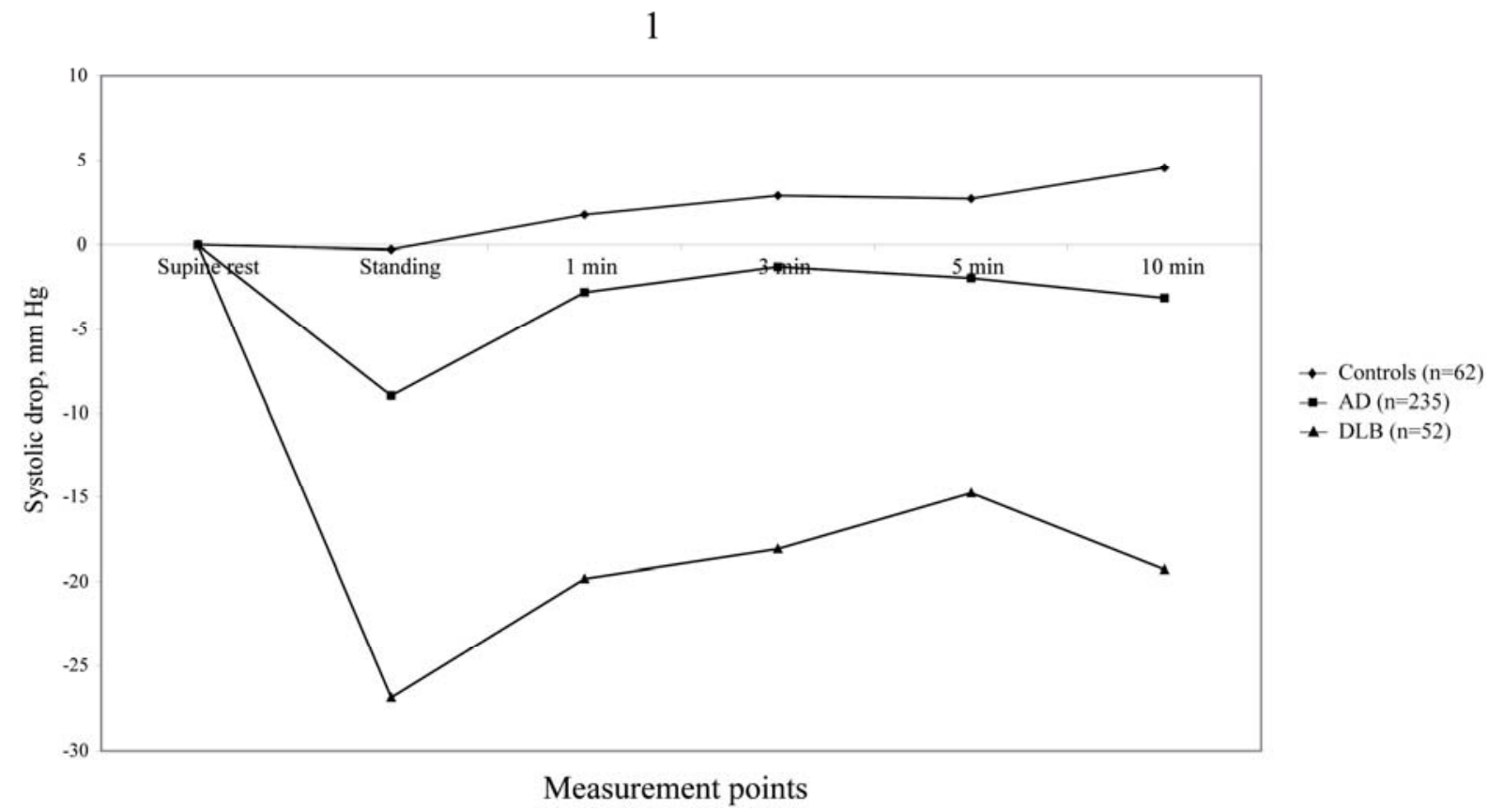

Figure 1. All included subjects $(\mathrm{n}=349)$. The mean BP after 10 minutes of rest in supine position was $141 \pm 18 / 80 \pm 8 \mathrm{~mm} \mathrm{Hg}$ (mean $\mathrm{SBP} \pm \mathrm{SD} /$ mean $\mathrm{DBP} \pm \mathrm{SD}$ ) for the controls, $147 \pm 23 / 83 \pm 12 \mathrm{~mm} \mathrm{Hg}$ for the AD patients and $150 \pm 21 / 81 \pm 10 \mathrm{~mm} \mathrm{Hg}$ for the DLB patients. The mean difference in systolic blood pressure from supine rest is shown. Differences were significant between AD and DLB on all measurement points $(\mathrm{p}<0.001)$, between DLB and controls on all measurement points $(\mathrm{p}<0.001)$ and between AD and controls on standing $(p<0.001), 5 \min (p=0.048)$ and $10 \min (p=0.003)$. 
$2 \mathrm{~A}$

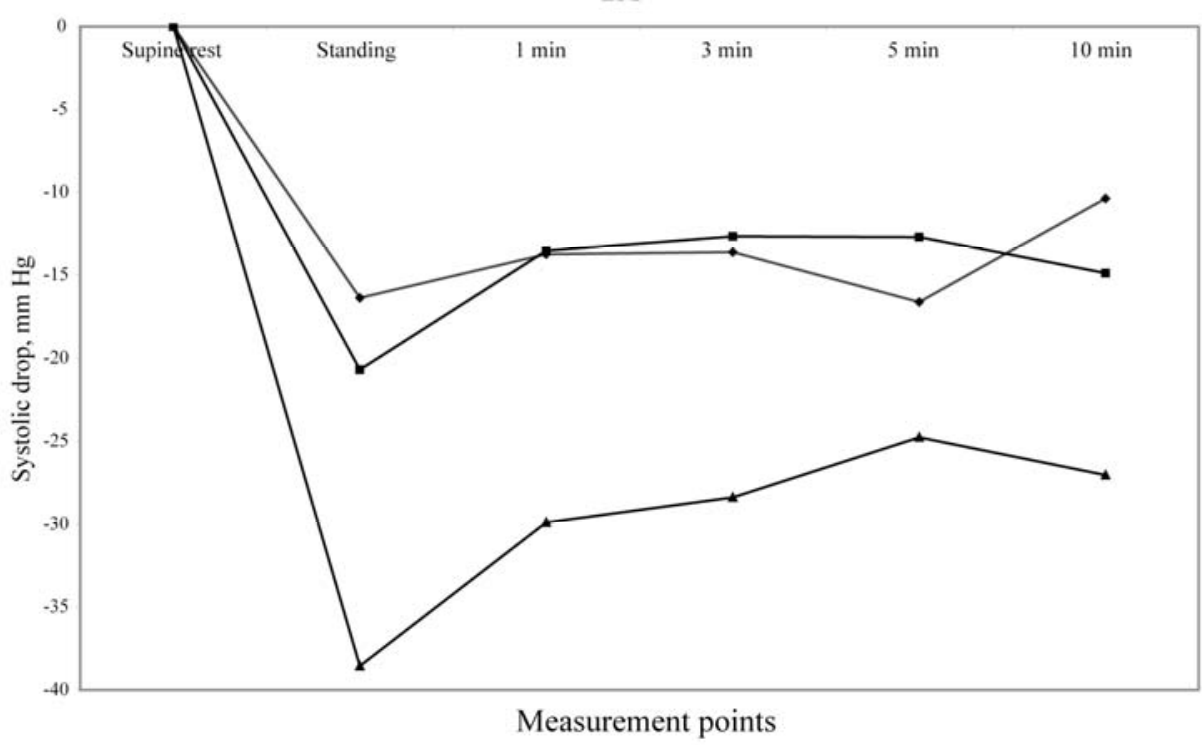

$\leftarrow$ Controls $(\mathrm{n}=8)$

- $\mathrm{AD}(\mathrm{n}=99)$

^ DLB $(\mathrm{n}=36)$

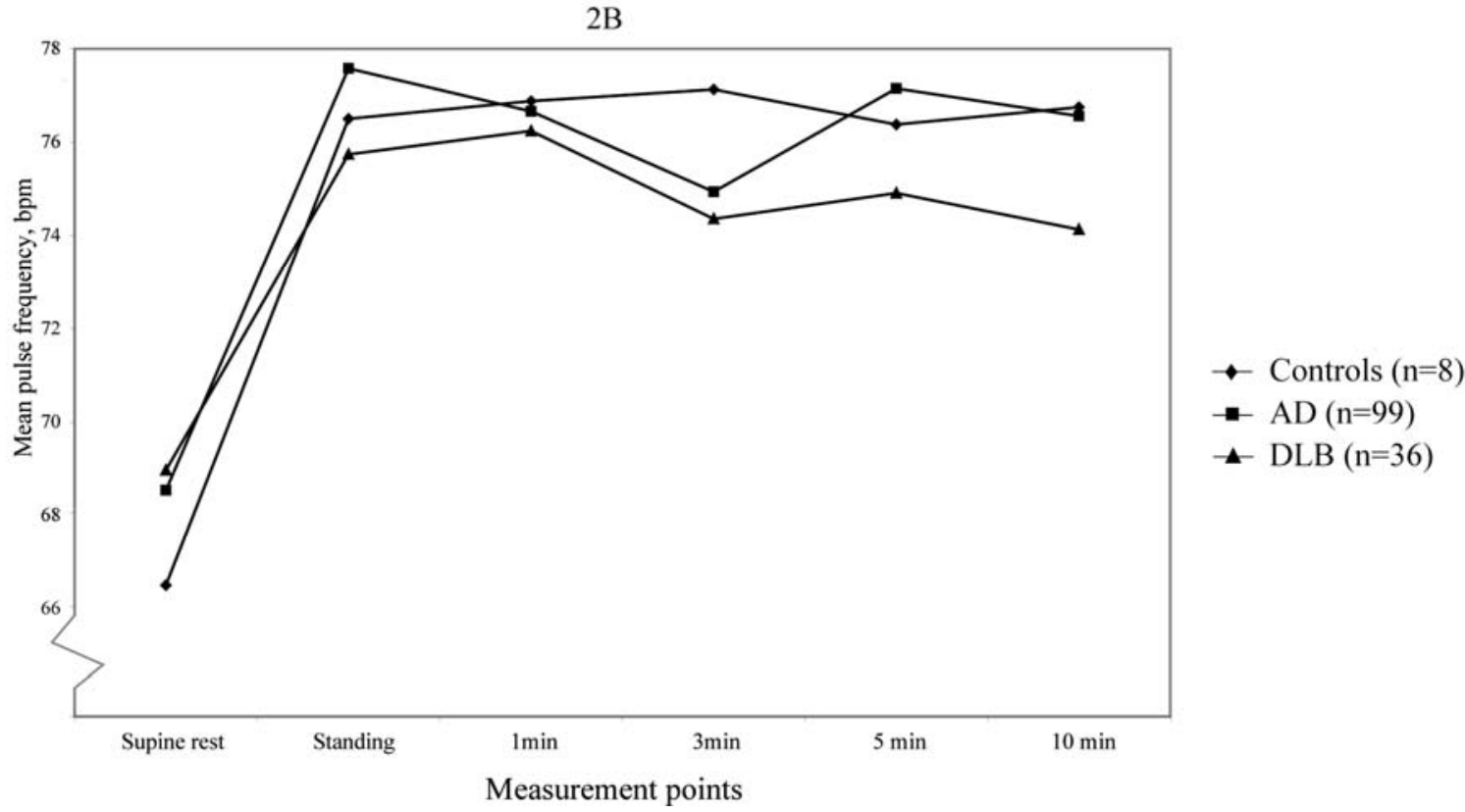

Figure 2. Orthostatic subjects ( $\mathrm{n}=143)$. (A) The mean BP after 10 minutes of rest in supine position was $143 \pm 16 / 81 \pm 7 \mathrm{~mm} \mathrm{Hg}$ (mean $\mathrm{SBP} \pm \mathrm{SD} /$ mean $\mathrm{DBP} \pm \mathrm{SD}$ ) for the controls, $154 \pm 25 / 86 \pm 13 \mathrm{~mm} \mathrm{Hg}$ for the AD patients and $151 \pm 22 / 81 \pm 10 \mathrm{~mm} \mathrm{Hg}$ for the DLB patients. The mean difference in systolic blood pressure from supine rest is shown. Differences were significant between AD and DLB on standing $(\mathrm{p}<0.001), 1 \min (\mathrm{p}<0.001), 3 \min (\mathrm{p}<0.001), 5$ $\min (p=0.002)$ and $10 \min (p=0.004)$. Differences were significant between DLB and controls on standing $(\mathrm{p}=0.001), 1 \mathrm{~min}(\mathrm{p}=0.016)$ and $10 \mathrm{~min}(\mathrm{p}=0.042)(\mathrm{B})$ Pulse frequencies on 
orthostatic challenge. The rise in heart frequency does not result in an adequate blood pressure response in the DLB group.

3

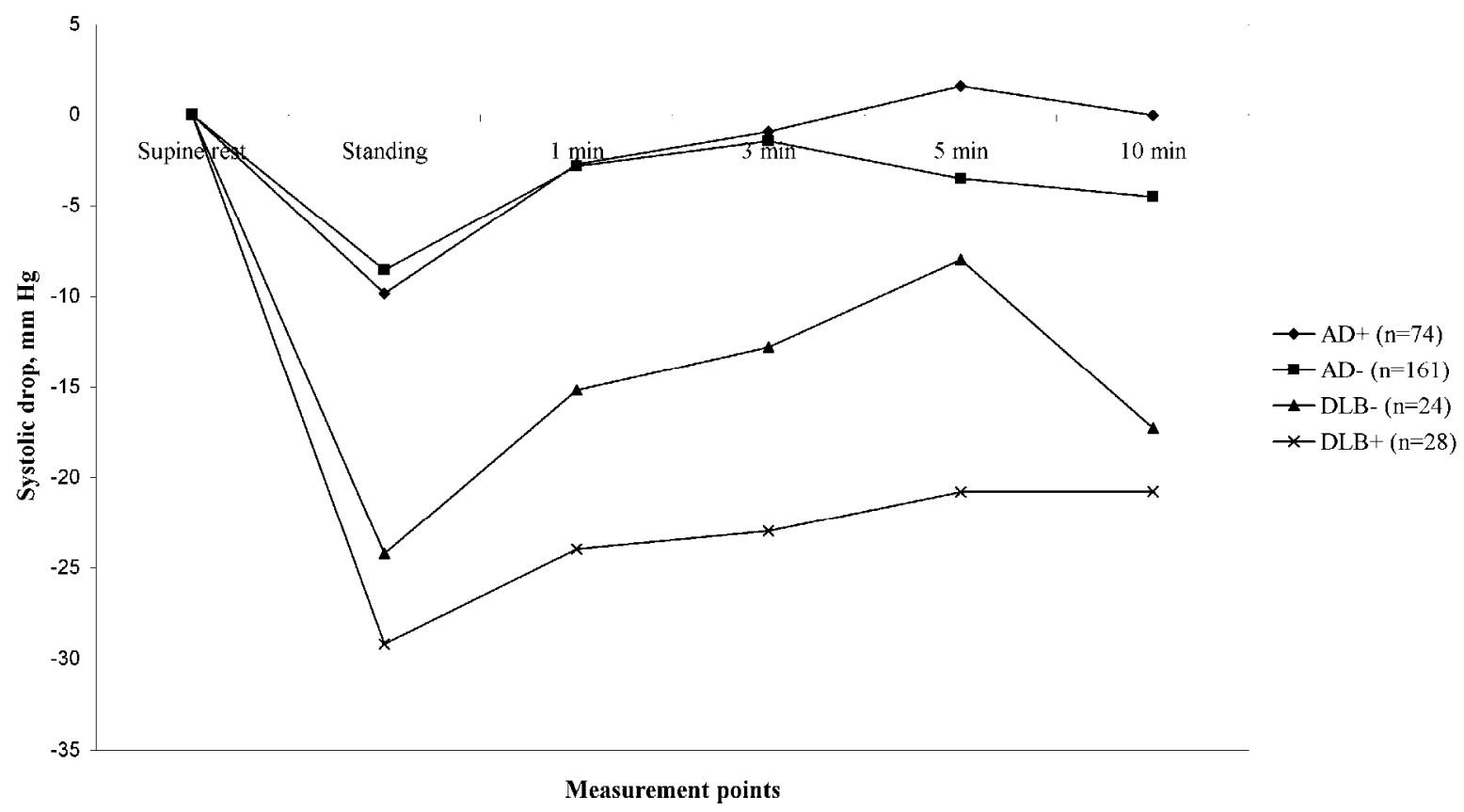

Figure 3. $\mathrm{AD}+(\mathrm{AD}$ with antipsychotics, anxiolytics, sedatives), $\mathrm{AD}-(\mathrm{AD}$ without antipsychotics, anxiolytics, sedatives), DLB- (DLB without antipsychotics, anxiolytics, sedatives), DLB+ (DLB with antipsychotics, anxiolytics, sedatives). All included subjects. The mean difference in systolic blood pressure from supine rest is shown. There were no significant differences between the DLB group with and the DLB group without medication. Differences were significant between the AD group with medication and the DLB group with medication on all measurement points $(\mathrm{p}<0.001)$. Differences were significant between the AD group without medication and the DLB group without medication on standing $(p=0.017)$, $1 \min (p=0.004), 3 \min (p=0.014)$ and $10 \min (p=0.009)$. 